\title{
Functional Vitamin B12 deficiency in Autism
}

Gregory Russell-Jones ( $\nabla$ russelljonesg@gmail.com )

Mentor Pharmaceutical Consulting Pty Ltd

\section{Research Article}

Keywords: Autism, Organic Acids Test, vitamin B12, cobalamin, Paradoxical B12 deficiency

Posted Date: March 2nd, 2022

DOI: https://doi.org/10.21203/rs.3.rs-1316855/v1

License: (c) (1) This work is licensed under a Creative Commons Attribution 4.0 International License. Read Full License 


\section{Abstract}

It has been known for over 40 years that dietary insufficiency of vitamin B12 in pregnant mothers can lead to vitamin B12 deficiency in the children and is often accompanied by developmental delay. In a previous study we found a deficiency of functional vitamin B2 in each members of a cohort 600 children and adults with a diagnosis of Autism Spectrum Disorder (ASD) of various ages (18 months to 34 years). The same cohort has also been assessed for functional vitamin B12 and each member of the cohort assessed was found to have functional vitamin B12 deficiency. The functional deficiency appeared to be related to the functional B2 deficiency, that was attributed to insufficient dietary lodine, Selenium and/or Molybdenum. The functional B12 deficiency occurred despite elevated serum B12 being found, and hence presents as Paradoxical vitamin B12 deficiency. As such, ASD due to functional B2 deficiency results in Paradoxical B12 deficiency, which differs from classical developmental delay due to vitamin B12 deficiency, as the later is correctable by administration of vitamin B12 alone. In contrast, ASD due to Paradoxical vitamin B12 deficiency, requires resolution of functional B2 deficiency before treatment with vitamin B12 can be effective.

\section{Introduction}

It has been known for over 40 years, that overt vitamin B12 deficiency in mothers can lead to psychomotor regression, failure to thrive, developmental delay, ASD and intellectual disability in the neonate $[1,2,3,4,5,6,7,8,9,10]$. Normally such deficiency is "overt" and is readily identified by low serum vitamin B12 in the mothers and child $[10,11,12,13,14,15,16,17,18]$. Overt vitamin B12 deficiency is more typical of diets low in vitamin B12, such as vegetarian or vegan diets $[6,12,18]$.

Standard measurement of serum vitamin B12 levels is performed on the assumption that the vitamin B12 measured is one of the active forms of vitamin B12, viz: Adenosyl or Methyl cobalamin, however, inactive forms such as cyanocobalamin, nitrosyl-cobalamin, hydroxycobalamin, sulfitocobalamin and $\mathrm{Co}(\mathrm{II})$ cobalamin are also measured and so will contribute to total serum B12. Hence serum B12 measurement is quantitative, but not qualitative. Potentially this could mean that a person may have high levels of serum cobalamin but be "suffering" from functional cobalamin deficiency, as despite the normal or elevated level of serum vitamin B12 measured the analogue that is measured may be largely inactive. There are two common markers of functional vitamin B12 deficiency, Methyl malonic acid (MMA) a marker for Adenosylcoblamin deficiency and homocysteine (Hcy) a marker of marker of functional Methylcobalamin deficiency, or lack of activity of methionine synthase. In addition, there are several other metabolic markers of functional vitamin B12 deficiency that are assessed in the Great Plains Laboratory (KS, USA) Urinary Organic Acids Test (OAT).

In a previous study [19], functional vitamin B2 sufficiency was assessed through the analysis of OAT data from a cohort of 600 children and adults with ASD. In the current communication, data from these OAT tests has been analysed to determine if the members of the cohort also have functional vitamin B12 deficiency. 


\section{Results}

Analysis of OAT data from the cohort of 600 individuals diagnosed with ASD revealed each and every individual within the cohort had a functional deficiency in vitamin B12 (see Figs. 1 to 3; Table 1). Thus, there increased levels of MMA, a marker of Adenosylcobalamin (Adenosyl B12) deficiency (See Fig. 1), as well as greatly increased levels of the neurotransmitter metabolites, HVA, VMA, 5HIAA, QA and KA (see Fig. 2-3, Table 1), which are characteristic of Methylcobalamin (Methyl B12 deficiency).

The degree of functional B12 deficiency was highly variable between ASD individuals as is reflected in the high standard deviation from the mean values (Table 1.)

Table 1

Functional Differences in Vitamin B12 -deficiency related markers between neurotypical (NT) persons and those with autism (ASD). Data is presented as Mean \pm STD

\begin{tabular}{|lll|}
\hline Marker & NT & ASD \\
\hline Methyl Malonic Acid & $0.66+/-0.21$ & $2.17 \pm 2.5$ \\
\hline Homovannilic Acid & $1.5 \pm 1.07$ & $6.35 \pm 5.88$ \\
\hline Vannillyl Mandelic Acid & $1.01 \pm 0.46$ & $2.93 \pm 1.64$ \\
\hline 5HIAA & $0.52 \pm 0.55$ & $7.28 \pm 16.55$ \\
\hline Quinolinic Acid & $1.12 \pm 0.65$ & $5.08 \pm 3.23$ \\
\hline Kynerunic Acid & $0.45 \pm 0.27$ & $2.64 \pm 3.64$ \\
\hline QA:KA & $3.12 \pm 2.05$ & $5.32 \pm 12.89$ \\
\hline
\end{tabular}

\section{Discussion}

Measurement of many markers in OAT indicated moderate to severe vitamin B12 deficiency in all individuals with a diagnosis of ASD, as analysed in the current study. Thus, levels of MMA, the "traditional" marker of Adenosyl B12 deficiency, were increased to as much as twenty-four times that of neurotypical individuals (Figure 1). Similarly, many less "traditional" markers associated with Methyl B12 deficiency were also elevated including KA, QA, 5HIAA, VMA, and HVA (Figures 2-3, Table 1).

According to the Equilibrium Law as expounded by Le Chatelier (Le Chatelier's Principle) any change in conditions that effect an equilibrium will result in a corresponding change to establish a new equilibrium. This principle can be used to "drive" reactions to produce or reduce the products of a reaction or the amount of a particular substrate in a reaction. Hence in a reaction $A+B$ ó $C+D$, one can increase the amount of product of the reaction $(C+D)$, if you increase $[A]$ or $[B]$ you can increase $[C]$ and/or [D]. 
This principle has particular relevance to two methylation reactions in the body, the production of Epinephrine (Adrenalin) by the methylation of Norepinephrine by the enzyme Phenylethanolamine-NMethyl transferase (PNMT)

Norepinephrine + SAM (PNMT) $=>$ Epinephrine and the production of Melatonin by the methylation of NAcetylserotonin by the enzyme Hydroxy-Indole-O-methyl transferase (HIOMT).

N-Acetylserotonin + SAM (HIOMT) $=>$ Melatonin

Both enzymes (PNMT and HIOMT) require the methylation cycle product, S-Adenosylmethionine (SAM) for activity.

Studies suggest that in conditions of reduced methylation the body adapts by trying to drive the production of Adrenalin and Melatonin by increasing the amount of the precursors, Dopamine and Norepinephrine (Adrenalin precursors) and N-Acetyl Serotonin and Serotonin (Melatonin precursors). This can be measured in OAT by increases in the degradation products HVA and VMA (Fig 2) as well as an increase in the levels of QA and KA (Figure 3) and 5HIAA (Table 1)

In a previous study [19], it was shown that each of the children assessed in this study was also found to be functionally deficient in vitamin B2. Given the absolute necessity for functional vitamin B2 (as FMN and FAD) for the activity of Methylene-tetrahydrofolate reductase (MTHFR) and methionine synthase reductase (MTRR), two essential enzymes in the regeneration of MethylCo(III)B12 [20, 21, 22, 23], it is intriguing to speculate that it is the original functional vitamin B2 deficiency that subsequently caused the functional vitamin B12 deficiency. In this respect this would mean that the developmental delay, as measured, is not simply a consequence of low vitamin B12 in the mothers, a known predisposing factor for ASD, but rather it could result from functional B2 deficiency, which then causes gradual inactivation of vitamin B12, resulting in functional B12 deficiency, which would be indistinguishable from absolute B12 deficiency in symptoms, but would be dismissed by the clinician due to there being normal or elevated serum vitamin B12 levels. Low functional B2, both through the reduced ability to make active B6 (PLP), also reduces the activity of the enzyme serine- hydroxymethyltransferase (SHMT) and then greatly reduces activity of the methylation cycle.

Hence (see Fig 4).

Reduced levels of active vitamin B2 as FMN and FAD also reduce the ability of the enzyme methionine synthase reductase to maintain the activity of the enzyme Methionine synthase. Thus, under conditions of functional B2 deficiency, the activity of Methionine Synthase reductase rapidly reduces and so too the function of Methionine Synthase. The result is that will be an accumulation of inactive Co(II)B12, which, because of the FMN/FAD deficiency, cannot be re-activated by MTRR and so will contribute to a large circulating pool of inactive serum vitamin B12. Studies looking at individuals with mutations in either methionine synthase or methionine synthase reductase have shown, that developmental delay is common $[24,25,26,27,28)$. Given that the identity of serum B12 is not routinely measured, it is only by 
looking at biochemical markers of deficiency, as has been done in this study, that there can be an accurate diagnosis of functional B12 deficiency in these children. Further, the consequence of vitamin B2 deficiency-mediated functional B12 deficiency, is that unless the functional B2 deficiency can be fixed, one can never fix the functional B12 deficiency.

Lack of methylation due to functional methyl B12 deficiency would also reduce the production of the Electron Transport System shuttle vector CoQ10, whose synthesis requires three methylation steps.

This in turn would reduce the energy transfer down the Electron Transport Chain (ETC), and reduce the amount of ATP produced inside the mitochondria of these individuals, and thereby reduce the energy available within the cytoplasm, which would have a profound effect on the highly energy dependent neurons, with a reduction in neuronal conduction speeds, and reduced brain plasticity, network function, and behavioural systems [29].

Apart from its role in the production of adrenalin, melatonin and CoQ10, over $40 \%$ of all SAM-derived methylation within the body is used in the synthesis of creatine [30]. In this process Guanidinoacetate is methylated using S-Adenosylmethionine as the methyl donor, via the enzyme Guanidinoacetate-Nmethyltransferase (GAMT, also known as GNMT) to form creatine, with separate enzyme systems in the liver and the brain [31,32]. Lack of production of creatine leads to Cerebral Creatine deficiency, which has been shown to be associated with a group of treatable intellectual development disorders, including many conditions including prominent speech delay, particularly in expressive and cognitive speech [32], autism, epilepsy, movement disorders, and myopathy [33, 34].

In a previous study we examined the mineral status of many of the ASD individuals within the current cohort and demonstrated that all children with ASD that were tested were deficient in one of more of lodine, Selenium and Molybdenum. In line with the need for all of lodine, Selenium and Molybdenum in the activation of vitamin B2, this deficiency was accompanied by an expected deficiency in functional vitamin B2. The current study demonstrates that the functional deficiency in vitamin B2, observed in the test cohort, leads to an expected deficiency in functional vitamin B12

It has been known for over 40 years that vitamin B12 deficiency in the neonate is associated with developmental delay in children $[14,28,33,34,35,36]$. These early studies were somewhat different to the current study in that the children with ASD in the previous studies had an absolute deficiency in serum vitamin B12. In contrast children in the current study have been found to have both a functional deficiency in vitamin B2 and a functional deficiency in vitamin B12 with normal to elevated serum B12. These findings would suggest that potentially the dramatic increase in the rate of ASD over the past 20 years could be due to decreases in the intake of lodine, Selenium and/or Molybdenum in countries, in which soil deficiencies of these minerals are now more common. Potentially this would suggest that lack of one single nutrient could be the precipitating event that results in the spectrum of developmental delays such as those seen in autism. Of note is the potential that any of the deficiencies would ultimately lead to reduced methylation and cerebral creatine deficiency, with the accompanying symptoms. 
The current studies fill a critical gap in the understanding of the mechanism behind the factors involved in developmental delay typical of ASD, and as such greatly aid in the understanding of the cause behind the condition and therefore provide a potential mechanism for the prevention and treatment of ASD.

Firstly, they support earlier studies in which lodine deficiency was found to be the single most preventable cause of developmental delay, and identify the pathway of vitamin B2 activation whereby a deficiency of any of lodine or Selenium or Molybdenum deficiency, would result in functional vitamin B2 deficiency.

Secondly, they describe how this functional deficiency in vitamin B2 would ultimately result in the eventual inactivation of vitamin B12 and so result in functional deficiency in vitamin B12, a known predisposing factor for developmental delay as typified in ASD.

Thirdly, through its role in the methylation cycle the studies identify critical methylation products which are essential for neurological development, including the production of melatonin, an essential molecule for the differentiation and maturation of neuronal stem cells into myelin producing oligodendrocytes, and importantly in the production of the energy transfer molecules, CoQ10 and creatine. In this regard a deficiency in creatine alone has been known to result in many of the symptoms typical of ASD.

\section{Methods}

\section{Study Sample}

Data analysis was carried out under the Australian National Health and Medical Research Council guidelines (NHMRC). Under these guidelines, all data was deidentified and steps were taken to ensure the anonymity and confidentiality of the data. Deidentification has consisted of absolute anonymity and confidentiality of the data, such that no specifics such as gender, ethnicity, Country of Origin, etc is associated with any data point in the study.

\section{As such per the NHMRC guidelines:}

1. The research does not carry any risk to the participants

2. The benefits of the research are many and will be of considerable benefit to any past, current or future participants, and as such represent no harm.

3. The data is from over 600 participants collected over 6 years and as such it would be impracticable to obtain consent from the participants. Further the participants had been notified at the time of analysis that data presented for analysis might potentially be used in research - but would be totally de-identified (which it has been).

4. There is no known reason why any of the participants would not have consented if they had been asked

5. Given the total de-identification of the data, there is absolute protection of their privacy 
6. Data is only housed in one location and has only been assessed by one person, and as such the confidentiality of the data can be assured.

7. No financial benefits from the data is anticipated, rather the data will be used to help prevent and treat those to whom the data applies.

8. The waiver is not prohibited by State, Federal or International Law.

A retrospective analysis was performed upon data submitted to us for analysis from a cohort of 600 children and adults who had been diagnosed with ASD from countries including USA, Canada, United Kingdom, Ireland, Germany, Spain, France, Italy, Bulgaria, India, Sweden, Bulgaria, Serbia, Dubai, Croatia and Australia. Age distribution of the 600 individuals was 1-5 (358); 6-10 (172); 11-15 (46); 16-20 (9); >21 (16). No selection was made in the acceptance of data, with no data being rejected. We were not made privy to either the methods of assessment nor of the severity of the Developmental Delay in the Children. Data is presented regardless of sex, or age. Ages varied from 1 year old to thirty-four years old. Organic Acid Test Data (600 sets, Great Plains Laboratories, Lenexa, KS, USA), which had been submitted to us for interpretation, by parents of children with autism spectrum disorder, (ASD) was compared to that from persons who were healthy, and who had no previously identified health condition (NT). Individual data is plotted as Scattergrams (see Graphs 1 to 3 ).

\section{Declarations}

\section{Compliance with Ethical Standards}

We declare that there are no potential conflicts of interest

Research did no involve human participants and/or animals.

No Informed consent is required, all data is "blinded" and as such is anonymous

\section{References}

1. Black M. M. Effects of vitamin B12 and folate deficiency on brain development in children. Food and nutrition bulletin, 29(2 Suppl), S126-S131. (2008).https://doi.org/10.1177/15648265080292S117

2. Jain, R., Singh, A., Mittal, M., \& Talukdar, B. Vitamin B12 deficiency in children: a treatable cause of neurodevelopmental delay. Journal of child neurology, 30(5), 641-643. (2015). https://doi.org/10.1177/0883073813516194

3. Rasmussen, S. A., Fernhoff, P. M., \& Scanlon, K. S. Vitamin B12 deficiency in children and adolescents. The Journal of pediatrics, 138(1), 10-17. (2001).https://doi.org/10.1067/mpd.2001.112160

4. Zhang, Y., Hodgson, N. W., Trivedi, M. S., Abdolmaleky, H. M., Fournier, M., Cuenod, M., Do, K. Q., \& Deth, R. C. Decreased Brain Levels of Vitamin B12 in Aging, Autism and Schizophrenia. PloS one, 11(1), e0146797. (2016).https://doi.org/10.1371/journal.pone.0146797 
5. Chu, J., Tu, Y., Chen, J., Tan, D., Liu, X., \& Pi, R. Effects of melatonin and its analogues on neural stem cells. Molecular and cellular endocrinology, 420, 169-179.

(2016).https://doi.org/10.1016/j.mce.2015.10.012

6. Smolka, V., Bekárek, V., Hlídková, E., Bucil, J., Mayerová, D., Skopková, Z., Adam, T., Hrubá, E., Kozich, V., Buriánková, L., Saligová, J., Buncová, M., \& Zeman, J. Metabolické komplikace a neurologické projevy pri deficitu vitaminu B12 u dětí vegetariánských matek [Metabolic complications and neurologic manifestations of vitamin B12 deficiency in children of vegetarian mothers]. Casopis lekaru ceskych, 140(23), 732-735 (2001).

7. Zengin, E., Sarper, N., \& Caki Kiliç, S. Clinical manifestations of infants with nutritional vitamin B deficiency due to maternal dietary deficiency. Acta paediatrica (Oslo, Norway : 1992), 98(1), 98-102. (2009). https://doi.org/10.1111/j.1651-2227.2008.01059.x

8. Halicioglu, O., Asik Akman, S., Sutcuoglu, S., Atabay, B., Turker, M., Akbay, S., \& Yaprak, I. Nutritional $\mathrm{B} \otimes \mathbb{Q}$ deficiency in infants of vitamin B怄-deficient mothers. International journal for vitamin and nutrition research. Internationale Zeitschrift fur Vitamin- und Ernahrungsforschung. Journal international de vitaminologie et de nutrition, 81(5), 328-334. (2011).https://doi.org/10.1024/0300$9831 / \mathrm{a} 000080$

9. Demir, N., Koc, A., Üstyol, L., Peker, E., \& Abuhandan, M. Clinical and neurological findings of severe vitamin B12 deficiency in infancy and importance of early diagnosis and treatment. Journal of paediatrics and child health, 49(10), 820-824. (2013). https://doi.org/10.1111/jpc.12292

10. Smith A. D. Maternal and infant vitamin B12 status and development. Pediatric research, 84(5), 591592. (2018). https://doi.org/10.1038/s41390-018-0110-0

11. Guez, S., Chiarelli, G., Menni, F., Salera, S., Principi, N., \& Esposito, S. Severe vitamin B12 deficiency in an exclusively breastfed 5-month-old Italian infant born to a mother receiving multivitamin supplementation during pregnancy. BMC pediatrics, 12, 85 (2012).https://doi.org/10.1186/14712431-12-85

12. Roed, C., Skovby, F., \& Lund, A. M. Svaer vitamin B12-mangel hos spaedbørn brysternaeret af veganere [Severe vitamin B12 deficiency in infants breastfed by vegans]. Ugeskrift for laeger, 171(43), 3099-3101 (2009).

13. Agrawal, S., \& Nathani, S. Neuro-regression in vitamin B12 deficiency. BMJ case reports, 2009, bcr06.2008.0235 (2009). https://doi.org/10.1136/bcr.06.2008.0235

14. Chalouhi, C., Faesch, S., Anthoine-Milhomme, M. C., Fulla, Y., Dulac, O., \& Chéron, G. Neurological consequences of vitamin B12 deficiency and its treatment. Pediatric emergency care, 24(8), 538-541 (2008).https://doi.org/10.1097/PEC.0b013e318180ff32

15. Lücke, T., Korenke, G. C., Poggenburg, I., Bentele, K. H., Das, A. M., \& Hartmann, H. Mütterlicher Vitamin-B12-Mangel: Ursache neurologischer Symptomatik im Säuglingsalter [Maternal vitamin B12 deficiency: cause for neurological symptoms in infancy]. Zeitschrift fur Geburtshilfe und Neonatologie, 211(4), 157-161 (2007).https://doi.org/10.1055/s-2007-981249 
16. Strucińska M. Dieta wegetariańska matki karmiacej piersia w świetle zaleceń zywieniowych [Vegetarian diets of breastfeeding women in the light of dietary recommendations]. Roczniki Panstwowego Zakladu Higieny, 53(1), 65-79 (2002).

17. Renault, F., Verstichel, P., Ploussard, J. P., \& Costil, J. Neuropathy in two cobalamin-deficient breastfed infants of vegetarian mothers. Muscle \& nerve, 22(2), 252-254(1999).. https://doi.org/10.1002/(sici)1097-4598(199902)22:2<252::aid-mus13>3.0.co;2-d

18. Weiss, R., Fogelman, Y., \& Bennett, M. Severe vitamin B12 deficiency in an infant associated with a maternal deficiency and a strict vegetarian diet. Journal of pediatric hematology/oncology, 26(4), 270-271 (2004). https://doi.org/10.1097/00043426-200404000-00013

19. Russell-Jones, G. J. Functional vitamin B2 deficiency in Autism Spectrum Disorder. (Manuscript in preparation) (2022)

20. García-Minguillán, C. J., Fernandez-Ballart, J. D., Ceruelo, S., Ríos, L., Bueno, O., Berrocal-Zaragoza, M. I., Molloy, A. M., Ueland, P. M., Meyer, K., \& Murphy, M. M. Riboflavin status modifies the effects of methylenetetrahydrofolate reductase (MTHFR) and methionine synthase reductase (MTRR) polymorphisms on homocysteine. Genes \& nutrition, 9(6), 435 (2014). https://doi.org/10.1007/s12263-014-0435-1

21. Olteanu, H., Wolthers, K. R., Munro, A. W., Scrutton, N. S., \& Banerjee, R. Kinetic and thermodynamic characterization of the common polymorphic variants of human methionine synthase reductase. Biochemistry, 43(7), 1988-1997 (2004). https://doi.org/10.1021/bi035910i

22. Shaik, M. M., \& Gan, S. H. (Vitamin supplementation as possible prophylactic treatment against migraine with aura and menstrual migraine. BioMed research international, 2015, 469529 2015).https://doi.org/10.1155/2015/469529

23. McNulty, H., Ward, M., Hoey, L., Hughes, C. F., \& Pentieva, K. Addressing optimal folate and related Bvitamin status through the lifecycle: health impacts and challenges. The Proceedings of the Nutrition Society, 78(3), 449-462 (2019).https://doi.org/10.1017/S0029665119000661

24. Hoffmann, GF \& Kolker S. Deficiencies of methionine synthase reductase (cobalamin E defect) and methionine synthase (cobalamin G defect). In Handbook of Clinical Neurology, Pediatric Neurology Part III (2013).

25. Hsueh, Y. M., Lin, Y. C., Chung, C. J., Huang, Y. L., Hsieh, R. L., Huang, P. T., Wu, M. Y., Shiue, H. S., Chien, S. N., Lee, C. Y., Lin, M. I., Mu, S. C., \& Su, C. T. Combined effect of polymorphisms of MTHFR and MTR and arsenic methylation capacity on developmental delay in preschool children in Taiwan. Archives of toxicology, 94(6), 2027-2038 (2020).https://doi.org/10.1007/s00204-020-02745-y

26. Harding, C. O., Arnold, G., Barness, L. A., Wolff, J. A., \& Rosenblatt, D. S. Functional methionine synthase deficiency due to cbIG disorder: a report of two patients and a review. American journal of medical genetics, 71(4), 384-390 (1997). https://doi.org/10.1002/(sici)10968628(19970905)71:4<384::aid-ajmg3>3.0.c0;2-u

27. Zavadakova, P., Fowler, B., Zeman, J., Suormala, T., Pristoupilová, K., Kozich, V., \& Zavad'áková, P. CbIE type of homocystinuria due to methionine synthase reductase deficiency: clinical and molecular 
studies and prenatal diagnosis in two families. Journal of inherited metabolic disease, 25(6), $461-$ 476 (2002).https://doi.org/10.1023/a:1021299117308

28. Hall C. A. Function of vitamin B12 in the central nervous system as revealed by congenital defects. American journal of hematology, 34(2), 121-127 (1990).https://doi.org/10.1002/ajh.2830340208

29. Vergara RC, Jaramillo-Riveri S, Luarte A, et al. The Energy Homeostasis Principle: Neuronal Energy Regulation Drives Local Network Dynamics Generating Behavior [published correction appears in Front Comput Neurosci. Oct 29;14:599670]. Front Comput Neurosci. 2019;13:49. Published 2019 Jul 23.( 2020 ). doi:10.3389/fncom.2019.00049

30. Brosnan, J. T., da Silva, R. P., \& Brosnan, M. E. The metabolic burden of creatine synthesis. Amino acids, 4O(5), 1325-1331 (2011).https://doi.org/10.1007/s00726-011-0853-y

31. da Silva, R. P., Nissim, I., Brosnan, M. E., \& Brosnan, J. T. Creatine synthesis: hepatic metabolism of guanidinoacetate and creatine in the rat in vitro and in vivo. American journal of physiology. Endocrinology and metabolism, 296(2), E256-E261 (2009).https://doi.org/10.1152/ajpendo.90547.2008

32. Schulze A. Creatine deficiency syndromes. Molecular and cellular biochemistry, 244(1-2), 143-150 (2003).

33. Dror, D. K., \& Allen, L. H. Effect of vitamin B12 deficiency on neurodevelopment in infants: current knowledge and possible mechanisms. Nutrition reviews, 66(5), 250-255 (2008).https://doi.org/10.1111/j.1753-4887.2008.00031.x

34. Kocaoglu, C., Akin, F., Caksen, H., Böke, S. B., Arslan, S., \& Aygün, S. Cerebral atrophy in a vitamin B12deficient infant of a vegetarian mother. Journal of health, population, and nutrition, 32(2), 367-371 (2014).

35. Stockler-Ipsiroglu, S., \& van Karnebeek, C. D. Cerebral creatine deficiencies: a group of treatable intellectual developmental disorders. Seminars in neurology, 34(3), 350-356 (2014).https://doi.org/10.1055/s-0034-1386772

36. Bousselamti, A., El Hasbaoui, B., Echahdi, H., \& Krouile, Y. Psychomotor regression due to vitamin B12 deficiency. The Pan African medical journal, 30, 152 (2018).https://doi.org/10.11604/pamj.2018.30.152.12046

37. Bravo J, P., Ibarra C, J., \& Paredes M, M. Compromiso neurológico y hematológico por déficit de vitamina B12 en lactante hijo de madre vegetariana: caso clínico [Hematological and neurological compromise due to vitamin B12 deficit in infant of a vegetarian mother: case report]. Revista chilena de pediatria, 85(3), 337-343 (2014).https://doi.org/10.4067/S0370-41062014000300010

38. Mercimek-Andrews, S., \& Salomons, G. S. Creatine Deficiency Syndromes. In M. P. Adam (Eds.) et. al., GeneReviews ${ }^{\circledR}$. University of Washington, Seattle.

39. Michaud, J. L., Lemieux, B., Ogier, H., \& Lambert, M. A. (1992). Nutritional vitamin B12 deficiency: two cases detected by routine newborn urinary screening. European journal of pediatrics, 151(3), 218220 (2009). https://doi.org/10.1007/BF01954389 


\section{Figures}

\section{Figure 1}

Methylmalonic acid in the urine of neurotypical (NT) and ASD individuals

\section{Figure 2}

HVA acid (Left Panel) and VMA (Right Panel) in the urine of neurotypical (NT) and ASD individuals

\section{Figure 3}

Quinolinic Acid (Left Panel) and Kynurenic Acid (right panel) in the urine of neurotypical (NT) and ASD individuals

\section{Figure 4}

Involvement of FMN/FAD and PLP in the Methylation cycle. Upper panel MTHFR and production of 5MTHF. Lower panel rejuvenation of MethylCo(III)Cbl from Co(II)Cbl via MTRR. S-AdoHcy $-S-$ Adenosylhomocysteine; S-AdoMet - S-Adenosylmethionine; MTHFR - Methylenetetrahydrofolate Reductase; MTR - Methioninesynthase; MTRR - methioninesynthase reductase; SHMT - Serinehydroxymethyltransferase; PLP - Pyridoxal phosphate; FAD - Flavin adeninedinucleotide; 5MTF - 5methylenetetrahydrofolate; 5,10-methylene THF - 5,10-methylene tetrahydrofolate 